\title{
High strain rate stress-strain response of soils - A review
}

\author{
Sunita Mishra ${ }^{\text {i) }}$, Tanusree Chakraborty ${ }^{\text {ii) }}$, Dipanjan Basu ${ }^{\text {iii) }}$
}

i) Ph.D. Student, Department of Civil Engineering, Indian Institute of Technology (IIT) Delhi, Hauz Khas, New Delhi - 110016 ii) Assistant Professor, Department of Civil Engineering, Indian Institute of Technology (IIT) Delhi, Hauz Khas, New Delhi - 110016 iii) Assistant Professor, Civil and Environmental Engineering, University of Waterloo, Waterloo, ON, Canada N2L 3G1

\begin{abstract}
In the current study, a review on the response of soils subjected to high strain rate loading is presented. High strain rate loading on soil may be applied through high loading rate uniaxial compression tests, triaxial tests, split Hopkinson pressure bar (SHPB) tests, and shock tube test. Herein, the results of SHPB tests from the literature have been reviewed and the effect of strain rate on the stress-strain response of soils, elastic modulus, initial inertia, peak and failure stresses of soils have been studied. The effects of strain rate, initial void ratio, confining pressure and saturation on the high strain rate response of soils are also discussed. The review thus provides complete understanding of soil behavior under high loading rates.
\end{abstract}

Keywords: high strain rate, SHPB, soil review

\section{INTRODUCTION}

Sustainable and resilient design of civil infrastructure requires that civil engineering structures can efficiently and economically resist anticipated as well as unanticipated loads, and can be functional with minimum repair and within reasonable time if subjected to extreme loads. Unanticipated loads can be caused by nature (e.g., tsunami, tornado and earthquake) or by human activities (e.g., bomb blast, rocket attack and collision). Some of the extreme loading events like blasts, sudden landslides and missile penetration may generate strain rates in soil of the order of $10^{4} / \mathrm{sec}$ (Ngo et al. 2007 and Dusenberry 2010) which may also lead to catastrophic failures. Soil is the weakest of all civil engineering materials and often plays a critical role in the failure of the structures under catastrophic events. Hence, in order for sustainable design of civil engineering facilities against rapidly acting unanticipated loads, it is essential that soils subjected to high strain rates are properly characterized and modelled. It is also necessary to understand the stressstrain response of soils under SHPB tests for different soil types based on their mineralogy, strain rates, initial void ratio, saturation, initial density and its behavior under different types of confinement for development of physics based constitutive model for sand. Omidvar et al. (2012) presented a review on the high strain rate loading response of the different sand tested by various researchers. The monotonic high strain rate tests was reviewed and the effect of high strain rate loading, initial void ratio, confining pressure, saturation and initial density on the confined modulus, stress-strain response, and shear strength of sand was studied. However, they did not report the effect of grain mineralogy on strain rate dependent stress-strain response of soils.

In the present work, the dynamic stress-strain response of the dry sand obtained by various researchers by performing split Hopkinson pressure bar test has been put together and the stress-strain response exhibited by the dry sand under high loading rate has been studied taking the insight deep into the grain shape, size and mineralogy.

\section{REVIEW OF LITERATURE}

Many researchers have performed high strain rate tests on soil by using split Hopkinson pressure bar (SHPB) device which have successfully produced the dynamic stress-strain response of soil. Felice et al. (1987) checked the repeatability of SHPB test results on soil by using multiple identical samples at a particular strain rate. The experiments were conducted on clayey silty sand specimens of diameter $60.9 \pm 0.5 \mathrm{~mm}$ which is the same as that of the pressure bars. Two different 
lengths $(l)$ of the specimens, e.g. $6.25 \mathrm{~mm}$ and $12.7 \mathrm{~mm}$ and aspect ratio $(l / d, d=$ diameter) of less than 0.2 were considered to achieve uniform loading and force equilibrium in the specimen. The soil specimens were tested under confining cylinder to prevent multiple loading. It was observed from the stress-strain response that the applied stresses and maximum strain rates for the experiments ranged from $130 \mathrm{MPa}$ to $760 \mathrm{MPa}$ and from $500 / \mathrm{sec}$ to $5000 / \mathrm{sec}$, respectively.

Charlie et al. (1990) performed SHPB tests on compacted specimens of 50/80 silica sand to analyse the influence of saturation on compression stress wave velocity, stress transmission and attenuation. The soil samples were prepared as $10.16 \mathrm{~cm}$ long and $5.08 \mathrm{~cm}$ in diameter $(d)$ with $1.6 \mathrm{~g} / \mathrm{cm}^{3}$ initial density. The results from the SHPB tests showed that the wave velocity, transmitted stress, and quasistatic confined modulus increase as the saturation level increases up to approximately 30 to $40 \%$ saturation with respect to dry state of the soil sample. For saturation levels between 40 to $95 \%$, wave speed and transmitted stress decrease with increasing saturation.

Again, Felice et al. (1991) conducted high strain rate analysis of two different soil types e.g., one on clayey soil from McCormick Ranch Test Site at Kirtland AFB, New Mexico and the other on dry desert alluvium from Yuma, Arizona. The initial moisture content of the clayey sand specimens and dry alluvium specimens were of $13.3 \%$ and $3 \%$ respectively. The lengths of the specimen tested were of $12.45 \mathrm{~mm}$ for clayey sand and $25 \mathrm{~mm}$ and $13 \mathrm{~mm}$ for dry desert alluvium. A confining cylinder was used to control the loading path and negate the effect of radial inertia and interface friction on specimen response. It may be noted that the standard split Hopkinson bar data reduction procedure assumes stress uniformity condition over the entire length of the specimen allowing the average stress- strain response to be computed and the specimen takes some initial time to achieve equilibration upon application of dynamic load. Felice et al. (1991) observed that the initial part of the stress-strain curve thus cannot be computed correctly with standard data reduction procedure. Hence, they used a modified Lagrangian analysis technique to compute the initial stress-strain response for the dynamically loaded samples. The corrected stress-strain response showed a peak stress of $100 \mathrm{MPa}$ for the clayey sand specimen and $11 \mathrm{MPa}$ for dry desert alluvium.

Shibusawa and Oida (1992) performed unconfined impact compression test on clay soil samples by using drop weight hammer to determine the high frequency equivalent Young's modulus and observed that the Young's modulus increased exponentially with water content. They also defined the low frequency equivalent Young's modulus as the initial gradient of a stressstrain curve which decreased exponentially with increase in water content. The high frequency (above 3 $\mathrm{kHz}$ ) equivalent Young's modulus was found to be one to two orders of magnitude larger than the low frequency one (below $50 \mathrm{~Hz}$ ). The high and the low frequency Young's moduli were calculated at about $17 \%$ water content of the soil samples where the soil samples behave like an elastic material with a unique Young's modulus value.. It was observed that water content, height of the soil samples and drop height affected the dynamic stress-strain relationships of the soil samples.

In 1994, Veyera studied the uniaxial stress-strain behaviour of compacted moist soil under onedimensional, undrained, confined compression loading at high strain rates of 1000-2000/sec. Three different types of soils e.g. Eglin sand, Tyndall sand and Ottawa 20-30 sand were tested and the stress-strain responses were studied. The soil specimens were prepared to lengths of $1.27 \mathrm{~cm}$ and $0.635 \mathrm{~cm}$ with diameter 5.08 $\mathrm{cm}$. The samples were tested with varying degrees of saturation under a confinement provided by thick walled stainless steel tube which is $7.62 \mathrm{~cm}$ long and $2.54 \mathrm{~cm}$ thick. It was observed that the stress-strain responses were dominated by the water content in the sample starting from the lock up strain limit. It was seen by comparing the results obtained for the three different soils that the slopes of the curves after the initial steep portion are nearly identical regardless of the initial saturation and soil type. The initiation of the lock up strain was observed to be different for each soil at the same saturation and the lock up was not seen in the Ottawa 20-30 sand below $80 \%$ saturation.

Bragov et al. (1994) performed jacket confined SHPB tests on plasticine (a material replicating the behaviour of clays) to study the dynamic deformation response. The jacket confining the soil specimen was made of steel having the yield strength of $1000 \mathrm{MPa}$. The axial stresses obtained in the specimens -did not exceed $170 \mathrm{MPa}$ for a strain rate ranging from 500 to $1400 /$ sec. It was concluded from the experiments that the shear strength parameters for plasticine for the strain rate of 1000 /sec agree reasonably well with the data for clays determined using static and quasi-static tests whereas the internal friction angle shows weak dependence on strain rate. In the similar line, Bragov et al. (2004) carried out dynamic tests of sand soil samples. The samples were prepared in elastic holder which produces axial and radial stresses uniformity in the sample. They prepared samples of $20 \mathrm{~mm}$ diameter and $9.5 \mathrm{~mm}$ length with $1.6 \mathrm{~g} / \mathrm{cm}^{3}$ initial density. 
Bragov et al. (2008) performed SHPB test to determine the material parameters for quartz sand for a wide range of strain rates. The samples of quartz sand were prepared with the same $20 \mathrm{~mm}$ diameter and $10 \mathrm{~mm}$ length but with an initial density of $1.5 \mathrm{~g} / \mathrm{cm}^{3}$. Analytical studies were carried out from the longitudinal and lateral stresses data obtained from the experiment. The results showed no abrupt change in behaviour with the change in strain rate whereas slight dependency of strain rate was witnessed with the change in pressure given by changing the length of the striker bar and velocity. The dynamic compaction process during the test involved two mechanisms - grain movement and grain fracture. The grain movement was observed at low strain rate regime whereas grain locking which leads to grain fracturing was witnessed in high strain rate regime.

Song et al. (2009) performed dynamic compression test on silica based fine grained, oven dried and poorly graded sand by using SHPB at various high strain rate. The samples of the same dimensions of $9.3 \mathrm{~mm}$ length and $19.05 \mathrm{~mm}$ diameter with a density of $1.5 \times 10^{3}$ $\mathrm{kg} / \mathrm{m}^{3}$ were prepared for quasistatic and dynamic tests and the confinement was provided by polycarbonate tube. The strain rate effect on the compressive stressstrain response of sand was investigated. Again, the samples of dry sand with density $1.6 \times 10^{3} \mathrm{~kg} / \mathrm{m}^{3}$ were prepared to study the effect of gas porosity, initial density and lateral confinement effect. The confinement was given by polyolefin heat shrinking tubes and 4340 steel tubes other than polycarbonate tube. The results showed that the compressive response of the dry sand is not strain rate sensitive under the loading conditions in the study considered by Song et al. (2009) whereas it showed dependency on initial density and lateral confinement. The stiffness increased by $20 \%$ when more rigid steel tube was used to confine the sand as compared to the polycarbonate tube. However, the stress drastically decreased when a polyolefin heat shrinking tube was used. It was also observed that the stress induced in the dry sand increases by $70 \%$ in the initial portion of the stress-strain response but then increases at decreasing rate with time (Song et al. 2009). The sands exhibit the highest peak stress upon confinement under hardened steel and the lowest peak stress upon confinement given by polyolefin tube. The peak stress observed with polycarbonate tube confinement is $25 \mathrm{MPa}$ which is $73.3 \%$ more than that with polyolefin tube, in the order of $3 \mathrm{MPa}$ and the peak stress with steel tube confinement is $35 \mathrm{MPa}$ which is $40 \%$ more than that of polycarbonate tube confinement. The soil samples tested using polyolefin tube as confinement gives very low and constant stress whereas when tested under polycarbonate and steel tube confinement gives linearly rising stress-strain response curve (Song et al. 2009).

Martin et al. (2009) studied the effect of moisture content on the high strain rate mechanical properties of the silica based fine grained oven dried and poorly graded sand by using a split Hopkinson pressure bar. The moisture content was varied by $3 \%$ to $20 \%$ by weight. The samples were confined in a hardened steel tube and loaded to a constant strain rate of $400 / \mathrm{sec}$ where force equilibrium was achieved. It was observed that partially saturated sand is more compressible than dry sand with the softest behaviour observed at $7 \%$ moisture content. The softening of the partially saturated sand is due to the heterogeneity of the material through complex interaction resulting in lubrication provided by pore water to the sand particles. In the highly saturated sand specimen, the pore water prohibits air displacement and assumes some of the load acting to stiffen the specimen. It was observed that partially saturated sand response shows significant high frequency oscillation. Frictional effect is also observed by the friction between the sand particles and the steel confinement which would increase the magnitude of the stress.

Kabir et al. (2010) investigated compressive mechanical behaviour of fine sand using SHPB device. The results showed that the compressive response of the fine sand is insensitive to strain rate under the experimented loading conditions but dependent on moisture content, initial density and lateral confinement which are varied systematically. The sand becomes stiffer if initial density or confinement pressure increases. The sand particle size become smaller after hydrostatic pressure and further smaller after dynamic axial loading.

From the literature review, it may be concluded that the peak stress of the sand increases with moisture content, initial density and type of lateral confinement. Table 1 summarizes the sample dimensions, initial density and type of sand samples used by different researchers. For the geological materials the longitudinal wave speeds are slower when compared to non-attenuating isotropic material and the low wave speed allowing the specimen to acquire stress equilibrium and constant strain rate. When a stress wave passes through a soil specimen, a stress gradient is developed if the slenderness ratio is large (typically greater than 1). In order to study the dynamic behaviour of the soil sample effectively, the slenderness ratio is kept as small as possible (typically less than 0.5 ) to achieve stress uniformity and a correct stress-strain response of the tested sample. 
Table 1: Samples prepared for dry sand by various scientists for SHPB tests.

\begin{tabular}{|c|c|c|c|}
\hline $\begin{array}{c}\text { Work } \\
\text { performed } \\
\text { by various } \\
\text { scientists }\end{array}$ & $\begin{array}{l}\text { Dimensions of } \\
\text { the sample } \\
\text { prepared }\end{array}$ & $\begin{array}{l}\text { Initial } \\
\text { density }\end{array}$ & $\begin{array}{c}\text { Mineralogy } \\
\text { and grain size } \\
\text { of the samples }\end{array}$ \\
\hline $\begin{array}{c}\text { Bragov et al. } \\
(2004)\end{array}$ & $\begin{array}{c}l=9.5 \mathrm{~mm}, d= \\
20 \mathrm{~mm}\end{array}$ & $\begin{array}{c}1.6 \\
\mathrm{~g} / \mathrm{cm}^{3}\end{array}$ & - \\
\hline $\begin{array}{c}\text { Bragov et al. } \\
(2008)\end{array}$ & $\begin{array}{c}l=10 \mathrm{~mm}, d= \\
20 \mathrm{~mm}\end{array}$ & $\begin{array}{c}1.5 \\
\mathrm{~g} / \mathrm{cm}^{3}\end{array}$ & Quartz sand \\
\hline $\begin{array}{l}\text { Charlie et al. } \\
\text { (1990) }\end{array}$ & $\begin{array}{l}l=10.16 \mathrm{~mm}, d \\
\quad=50.8 \mathrm{~mm}\end{array}$ & $\begin{array}{c}1.6 \\
\mathrm{~g} / \mathrm{cm}^{3}\end{array}$ & $\begin{array}{c}\text { 50/80 silica } \\
\text { sand, Sub- } \\
\text { rounded quartz }\end{array}$ \\
\hline $\begin{array}{c}\text { Veyera and } \\
\text { Ross (1995) }\end{array}$ & \multirow{3}{*}{$\begin{array}{c}l=12.7 \mathrm{~mm} \& \\
6.35 \mathrm{~mm}, d= \\
50.8 \mathrm{~mm}\end{array}$} & $\begin{array}{l}1.67 \\
\mathrm{~g} / \mathrm{cm}^{3}\end{array}$ & $\begin{array}{c}\text { Eglin sand: } \\
\text { angular to sub } \\
\text { angular sand, } \\
7 \% \text { fines }\end{array}$ \\
\hline $\begin{array}{l}\text { Veyera and } \\
\text { Ross (1995) }\end{array}$ & & $\begin{array}{l}1.63 \\
\mathrm{~g} / \mathrm{cm}^{3}\end{array}$ & $\begin{array}{l}\text { Tyndall sand: } \\
\text { uniform, sub } \\
\text { angular sand } \\
\text { with no fines }\end{array}$ \\
\hline $\begin{array}{l}\text { Veyera and } \\
\text { Ross (1995) }\end{array}$ & & $\begin{array}{l}1.72 \\
\mathrm{~g} / \mathrm{cm}^{3}\end{array}$ & $\begin{array}{l}\text { Ottawa sand: } \\
\text { 20-30 sand, sub } \\
\text { rounded to } \\
\text { rounded, no } \\
\text { fines } \\
\end{array}$ \\
\hline $\begin{array}{l}\text { Felice et al. } \\
\text { (1991) }\end{array}$ & - & $\begin{array}{l}2.12 \\
\mathrm{~g} / \mathrm{cm}^{3}\end{array}$ & $\begin{array}{c}\text { Clayey sand, } \\
13.3 \% \text { water } \\
\text { content } \\
\end{array}$ \\
\hline $\begin{array}{l}\text { Felice et al. } \\
\text { (1991) }\end{array}$ & - & $\begin{array}{l}1.77 \\
\mathrm{~g} / \mathrm{cm}^{3}\end{array}$ & $\begin{array}{c}\text { Dry desert } \\
\text { alluvium, 3\% } \\
\text { water content }\end{array}$ \\
\hline $\begin{array}{l}\text { Felice et al. } \\
\text { (2009) }\end{array}$ & $\begin{aligned} l & =12.7 \mathrm{~mm}, d \\
& =60.9 \mathrm{~mm}\end{aligned}$ & $\begin{array}{l}1.87 \\
\mathrm{~g} / \mathrm{cm}^{3}\end{array}$ & $\begin{array}{c}\text { Quartz sand } \\
60 \% \text {, Feldspar } \\
30 \%, 13.3 \% \\
\text { water content }\end{array}$ \\
\hline $\begin{array}{c}\text { Song et al. } \\
\text { (2009) }\end{array}$ & \multirow{2}{*}{$\begin{array}{c}l=9.3 \mathrm{~mm}, d= \\
19.05 \mathrm{~mm}\end{array}$} & \multirow{2}{*}{$\begin{array}{c}1.5 \\
\mathrm{~g} / \mathrm{cm}^{3}\end{array}$} & \multirow{2}{*}{$\begin{array}{c}\text { Silica based } \\
\text { fine grain sand, } \\
\text { kiln dried and } \\
\text { poorly graded }\end{array}$} \\
\hline $\begin{array}{l}\text { Martin et al. } \\
(2009)\end{array}$ & & & \\
\hline
\end{tabular}

\section{COMPILATION OF RESULTS AND DISCUSSION}

In the present study, the dynamic stress-strain response obtained from experiments performed by various scientists and researchers as given in Table 1 are complied and presented in Fig. 1. It is observed from the Fig. 1 that the response of the sand tested by Bragov et al. (2004) exhibits a higher slope than the sand tested by Bragov et al. (2008) due to its higher density of $1.6 \mathrm{~g} / \mathrm{cm}^{3}$ as compared to $1.5 \mathrm{~g} / \mathrm{cm}^{3}$. The grains in a denser sample may show higher initial inertia and thus stiff stress-strain response initially. The sands however followed the similar trend to failure under varying axial pressures of $80 \mathrm{MPa}, 150 \mathrm{MPa}$ and $500 \mathrm{MPa}$. In the study by Veyera and Ross (1995), the
Eglin sand, Tyndall sand and Ottawa sand exhibited different stress-strain response which can be justified based on the soil mineralogy, grain shape and size and the strain rate at which the sands were tested. It may be noted that the grains of Eglin sand are angular to sub angular in shape with 7\% fines; the grains of Tyndall sand are uniform, sub angular in shape with no fines and the grains of Ottawa 20-30 sand are sub rounded to rounded in shape with no fines. These samples were prepared with initial density of $1.67 \mathrm{~g} / \mathrm{cm}^{3}$ for Eglin sand, $1.63 \mathrm{~g} / \mathrm{cm}^{3}$ for Tyndall sand and $1.72 \mathrm{~g} / \mathrm{cm}^{3}$ for 20-30 Ottawa sand. The explanation of different stressstrain curve of sands may be given in terms of the wave speed in different sand samples as given in the following sections.

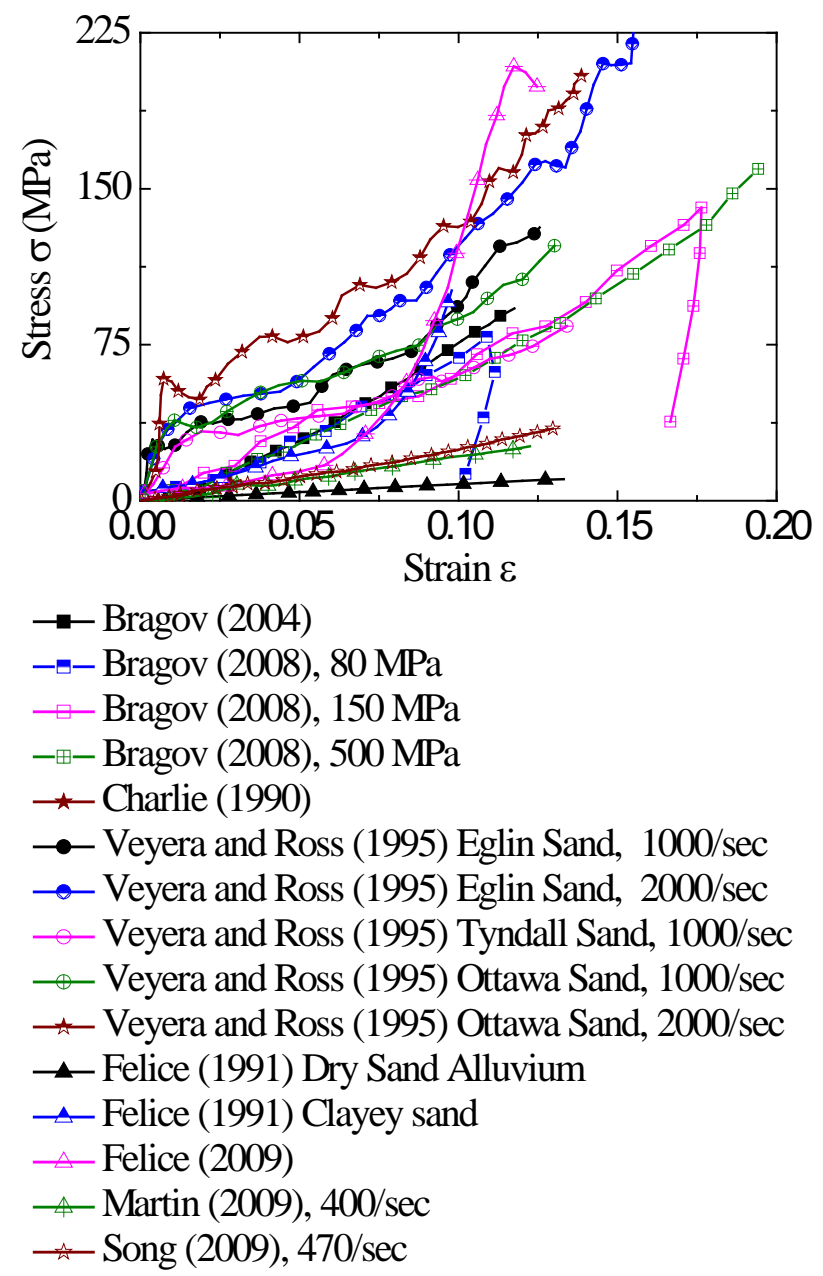

Fig. 1. Stress-strain response of different dry sands tested by various scientists and researchers using SHPB device

In the theory of SHPB, the velocity of the wave which passes through the specimen is given by 


$$
C=\sqrt{\frac{E}{\rho}}
$$

where, $C$ is the wave velocity in the specimen, $E$ is the Young's modulus of the specimen and $\rho$ is the density of the specimen. The above equation no. 1 signifies that the density of the material is inversely proportional to wave velocity passing through it. Assuming that the stress equilibrium and the uniform deformation of the sample prevail during dynamic loading, the strain rate is given by

$$
\dot{\varepsilon}(t)=-\frac{C}{l} \varepsilon_{\mathrm{r}}
$$

where, $\dot{\varepsilon}(t)$ is the strain rate produced in the specimen, $\varepsilon_{\mathrm{r}}$ is the reflected strain pulse measured by the incident bar strain gauge, $l$ is the initial length of the specimen prepared and $C$ is the wave velocity in the bar. The wave velocity passing through the 20-30 Ottawa sand sample is less than the wave velocity passing through Tyndall sand sample as the density of Ottawa sand is $1.72 \mathrm{~g} / \mathrm{cm}^{3}$ and Tyndall sand is $1.63 \mathrm{~g} / \mathrm{cm}^{3}$. At constant strain rate of $1000 / \mathrm{sec}$ with same length of specimen, when the wave velocity of Ottawa sand is less than Tyndall sand, the strain produced in Ottawa sand is more than Tyndall sand for a given time period. This implies that the slope of the stress-strain response of 2030 Ottawa sand will be more than the stress-strain response of Tyndall sand which is seen clearly from the Fig. 1 . The curves compared herein can also be justified by taking the initial density as a comparative parameter. Since, the initial density of Ottawa sand is more than Tyndall sand, the slope of the stress-strain response curve of Ottawa sand is more than Tyndall sand at the same strain rate and length of the specimen. At higher strain rates, the sample is observed to be more sensitive to dynamic loads presenting higher slopes at higher strain rate and the same can be justified by the results obtained by Veyera and Ross (1995) from SHPB test. The grain of Eglin sand is angular in shape and for Ottawa sand is rounded in shape. A comparative study based on the strain rate with respect to grain shape has been made in order to justify the exhibited stress-strain behaviour upon dynamic loading as seen in Fig. 1. At a strain rate of 1000/sec, the angular grains of Eglin sand undergoes interlocking and exhibits higher dynamic strength than with the rounded grains of Ottawa sand. When the strain rate of $2000 / \mathrm{sec}$ is applied, the angular grains of Eglin sand undergoes rupture and hence exhibit lower dynamic strength in comparison to the rounded grains of Ottawa sand which undergoes volumetric expansion at higher strain rate.
From the results reported in Felice et al. (1991) on clayey sand samples and dry desert alluvium samples and Felice et al. (2009) on quartz sand, as presented in Fig. 1, it is observed that the dry desert alluvium exhibits the least slope in stress-strain response. The dry desert alluvium is the loose unconsolidated soil sediments which causes lowest elastic modulus of this sample. The stress-strain response curve of clayey sand from Felice et al. (1991) and quartz sand from Felice et al. (2009) exhibit almost similar trend and follows same path upon loading. The peak stress obtained for quartz sand is more than clayey sand because of the presence of quartz in quartz sand as opposed to the presence of clay particles in the other sand. The presence of clay particles in sand makes the interface between the grains less frictional thus causing lesser peak stress. The interlocking force existing between the particles of quartz sand leads to increasing slope of stress-strain response. The stress-strain curve reported in Song et al. (2009) at 470/sec exhibits higher stress that that reported in Martin et al. (2009) at 400/sec which is reasonable.

\section{CONCLUSIONS}

It can be concluded from the present study that the dynamic response of sand depends on various factors like soil mineralogy, initial density of the sample prepared, saturation and lateral confinement. Different samples of dry sand prepared with various dimensions and densities tested by various researchers under dynamic loading applied by SHPB device has been reviewed in the present work. The following conclusions are made:

- The slope of the stress-strain curve is more if the samples are loaded dynamically at a constant strain rate and higher initial density as compared to the samples subjected to static load and dynamic load at lower initial density.

- The peak stress and elastic modulus is more for samples with angular grains than that with fine grains because of interlocking of the sand particles. But with increasing the strain rate, the rounded fine grain sample undergoes volumetric expansion and exhibit higher stress.

- The dry sand is less sensitive to strain rate as compared to saturated sand.

- If clay particles are present, it prevents the sand particles from interlocking making the sand samples weak and less frictional. The absence of clay particles allows interlocking of the sand particles resulting in higher peak stress response. 


\section{REFERENCES}

1) Bragov, A. M., Grushevsky, G. M., and Lomunov, A. K. (1994). "Use of the Kolsky method for studying shear resistance of soils.” DYMAT Journal, 1(3), 253-259.

2) Bragov, A. M., Kotov, V. L., and Lomunov, A. K. (2004). "Measurement of the dynamic characteristics of soft soils using the Kolsky method." Journal of Applied Mechanics and Technical Physics, 45(4), 580-585.

3) Bragov, A. M., Lomunov, A. K., Sergeichev, I. V., Tsembelis, K., and Proud, W. G. (2008). "Determination of physicomechanical properties of soft soils from medium to high strain rates." International Journal of Impact Engineering, 35, 967-976.

4) Charlie, W. A., Ross, C. A., and Pierce, S. J. (1990). "Split Hopkinson pressure bar testing of unsaturated sand." Geotechnical Testing Journal, 13(4), 291-300.

5) Dusenberry, D. O. (2010). "Handbook for blast resistant design of buildings." John Wiley and Sons, First Edition, 512.

6) Felice, C. W., Gaffney, E. S., Brown, J. A., and Olsen, J. M. (1987). "Dynamic high stress experiments on soil." Geotechnical Testing Journal, 10(4), 192-202.

7) Felice, C. W., Gaffney, E. S., and Brown, J. A. (1991). "Extended split Hopkinson bar analysis for attenuating materials." Journal of Engineering Mechanics, 117(5), 1119-1135.

8) Kabir, M. E., Song, B., Martin, B. E., and Chen, W. (2010). "Compressive behavior of fine sand." SANDIA REPORT, SAND2010-2289.

9) Martin, B. E., Chen, W., Song, B., and Akers, S. A. (2009). "Moisture effects on the high strain-rate behavior of sand." Mechanics of Materials, Elsevier Ltd, 41(6), 786-798.

10) Ngo, T., Mendis, P., Gupta, A. and Ramsay, J. (2007). "Blast loading and blast effects on structures - an overview." Electronic Journal of Structural Engineering Special Issue: Loading on Structures, 76-91.

11) Omidvar, M., Iskander, M., and Bless, S. (2012) "Stressstrain behavior of sand at high strain rates." International Journal of Impact Engineering, 49, 192-213.

12) Shibusawa, S., and Oida, A. (1992). "Dependency of observation parameters on soil dynamic parameters in unconfined impact compression tests.” Journal of Terramechanics, 29(3), 289-306.

13) Song, B., Chen, W., and Luk, V. (2009). "Impact compressive response of dry sand." Mechanics of Materials, 41(6), 777-785.

14) Veyera, G. E. (1994). "Uniaxial stress-strain behavior of unsaturated soils at high strain rates." Wright Laboratory Flight Dynamics Directorate, Air Force Material Command, Tyndall AFB 32403-5323.

15) Veyera, G. E., and Ross, C. A. (1995). "High strain rate testing of unsaturated sands using a split hopkinson pressure bar." Proceedings of Third International Conference on Recent Advances in Geotechnical Earthquake Engineering and Soil Dynamics, April 2-7,1995, Volume 1, St. Louis, Missouri, 31-34. 